\title{
A Case of Dural Arteriovenous Fistula Mimicking a Cerebellar Tumor
}

The Neurohospitalist

2018, Vol. 8(3) I58-159

(C) The Author(s) 2017

Reprints and permission:

sagepub.com/journalsPermissions.nav

DOI: $10.1177 / 1941874417726257$

journals.sagepub.com/home/ $\mathrm{NHO}$

(S)AGE

\author{
Sung-Min Cho, DO', Andrew B. Buletko, MD', Payal Patel, MD', \\ Russell Cerejo, MD', and Mark Bain, MD'
}

Keywords

dural arteriovenous fistula, intracranial mass, MRI brain, cerebral angiogram

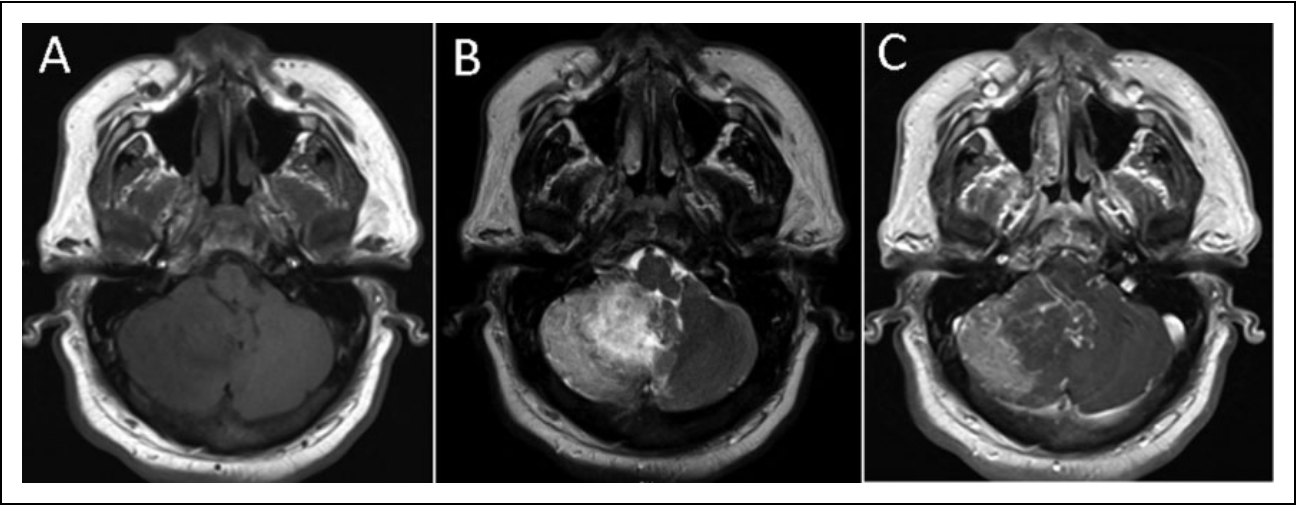

Figure I. Initial magnetic resonance imaging (MRI) of the brain with and without contrast showing a large right cerebellar mass lesion. The cerebellar mass was isointense on TI-weighted imaging (A), heterogeneously T2 hyperintense (B), and showed parenchymal and leptomeningeal enhancement on postgadolinium TI-weighted imaging (C).

\section{Case Presentation}

A 49-year-old healthy male presented to his local hospital with intractable headache, nausea, and ataxia. Initial gadolinium-enhanced magnetic resonance imaging (MRI) of the brain revealed an enhancing cerebellar mass lesion with vasogenic edema (Figure 1). A computed tomography scan of the chest, abdomen, and pelvis was unremarkable. He underwent biopsy for a presumptive diagnosis of a cerebellar tumor. The pathology showed nonspecific reactive changes without inflammation or malignant cells. An extensive infectious and autoimmune serological workup was negative and the patient was placed on long-term steroids and his symptoms improved. Vascular imaging was not performed at this time.

Six months later, his symptoms recurred with nausea and unsteady gait and presented to our center. His neurological examination was unremarkable except for right gaze-evoked nystagmus. Repeat MRI of the brain again showed a cerebellar mass lesion with leptomeningeal enhancement. The MRI of the spine was unremarkable. Cerebrospinal fluid (CSF) evaluation revealed 430 red blood cells $/ \mu \mathrm{L}, 12$ white blood cells $/ \mu \mathrm{L}$ ( $88 \%$ lymphocytes), $74 \mathrm{mg} / \mathrm{dL}$ protein, and $67 \mathrm{mg} / \mathrm{dL}$ glucose (103 mg/dL serum glucose). Extensive serum and CSF infectious, inflammatory, and malignancy workup was negative including testing for human immunodeficiency virus, herpes simplex virus-1/2, JC virus, varicella-zoster virus, Epstein-Barr virus, syphilis, cryptococcus, enterovirus. In addition, neuromyelitis optica antibody, paraneoplastic antibodies, cytology, IgG index, oligoclonal bands, and CSF bacterial and fungal cultures were negative. A positron emission tomography scan of the whole body including the brain was negative. A cerebral angiogram revealed an early and slow right cerebellar draining vein, consistent with a dural arteriovenous fistula (DAVF; Figure 2). The patient had a microsurgical ligation of the arterialized vein, which was exiting the tentorium and travelling along the superior

\footnotetext{
'Neurological Institute, Cleveland Clinic, Cleveland, OH, USA

Corresponding Author:

Sung-Min Cho, Neurological Institute, Cleveland Clinic, 9500 Euclid Ave, SI00, Cleveland, OH 44I95, USA.

Email: csmfisher@gmail.com
} 


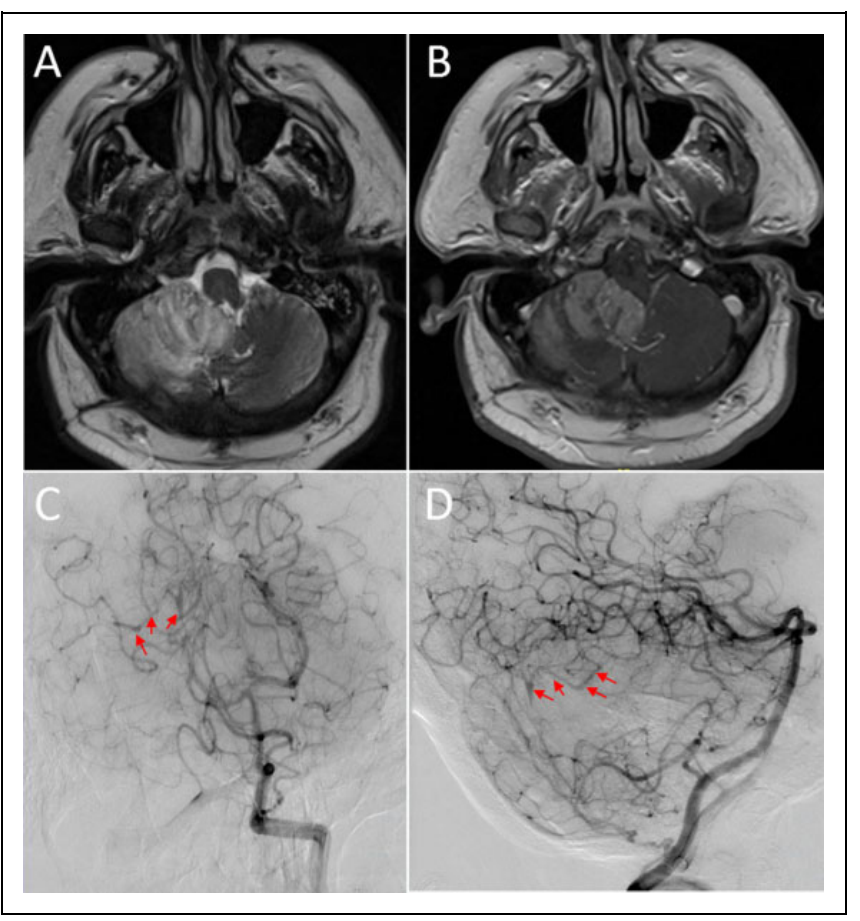

Figure 2. Repeat magnetic resonance imaging (MRI) of the brain showing an enhancing right cerebellar mass on T2-weighted imaging (A) and TI-weighted imaging with contrast (B). Cerebral angiogram anterior-posterior view (C) and lateral view (D) showing an early draining right hemispheric cerebellar vein (arrows) originating in the superior posterior right cerebellar hemisphere below the tentorium with arterial feeders from the posterior meningeal artery.

surface of the cerebellum. The patient's symptoms improved after the ligation.

The natural history of DAVF is unpredictable, and due to variable clinical presentations (from asymptomatic to intracranial hemorrhage) and neuroimaging features, the diagnosis of DAVF is often delayed or missed..$^{1-3}$ In this case, the DAVF mimicked a cerebellar tumor. Clinicians should be aware of and suspect this condition in patients with progressive focal neurological symptoms and atypical mass lesions, especially if there is a suggestion of abnormal vasculature on postcontrast images or because of the presence of flow voids.

\section{Authors' Note}

Drs Cho, Buletko, Patel, Cerejo, and Bain were directly involved with patient care and clinical decisions. Dr Cho prepared the first draft. Drs Buletko, Patel, Cerejo, and Bain edited. Dr Cho finalized the manuscript.

\section{Declaration of Conflicting Interests}

The authors declared no potential conflicts of interest with respect to the research, authorship, and/or publication of this article.

\section{Funding}

The authors received no financial support for the research, authorship, and/or publication of this article.

\section{References}

1. Youssef PP, Schuette AJ, Cawley CM, Barrow DL. Advances in surgical approaches to dural fistulas. Neurosurgery. 2014; 74(suppl 1):S32-S41.

2. Ishihara $\mathrm{H}$, Ishihara $\mathrm{S}$, Okawara $\mathrm{M}$, et al. Two cases of a dural arteriovenous fistula mimicking a brain tumor. Interv Neuroradiol. 2009;15(1):77-80.

3. Ghobrial GM, Marchan E, Nair AK, et al. Dural arteriovenous fistulas: a review of the literature and a presentation of a single institution's experience. World Neurosurg. 2013;80(1-2):94-102. 